\title{
Enhancing Intercultural Collaborative Learning in a Multinational Classroom: Case of Taiwan
}

\author{
June S. Chen ${ }^{1} \&$ Lavanchawee Sujarittanonta ${ }^{2}$ \\ ${ }^{1}$ Graduate Institute of Educational Policy and Leadership, Tamkang University, New Taipei City, Taiwan \\ ${ }^{2}$ Silpakorn University International College (SUIC), Bangkok, Thailand \\ Correspondence: June S. Chen, Graduate Institute of Educational Policy and Leadership, Tamkang University, \\ New Taipei City, Taiwan. E-mail: junechen@mail.tku.edu.tw
}

Received: June 24, 2014 Accepted: July 2, 2014 Online Published: July 11, 2014

doi:10.5539/ass.v10n15p221

URL: http://dx.doi.org/10.5539/ass.v10n15p221

\begin{abstract}
With more international programs being offered by universities in Asia nowadays, students have the opportunity to study together with foreign classmates. However, in practice, there exists a level of mistrust and apprehension between local and foreign students, especially among those with different physical appearances and distant cultural backgrounds. This research aimed to identify and understand intercultural obstacles to in-class collaboration among local Taiwanese students and their foreigner classmates in a Taiwan international college. Data were collected through an open-ended questionnaire and participant observation from 52 students of different nationalities (Haitian, Indian, Malaysian, Indonesian, Thai, American-Chinese, New Zealand-Chinese, Mongolian and Taiwanese). In order to minimize cultural bias, two researchers jointly conducted content analysis in combination with ethnographic observation. This study found that differences in physical appearance and communication styles strongly deterred intercultural communication among the students in the beginning. It was found that in-class group discussions and group projects helped to dispel negative stereotypes, by cultivating greater mutual respect and understanding among the students in a multinational classroom. In fact, several misunderstandings and cultural conflicts could have been resolved in the classroom. Findings suggest that teachers have a crucial role in developing students' intercultural competence by implementing collaborative learning methods.
\end{abstract}

Keywords: intercultural, collaborative learning, xenophobia, multinational classroom

\section{Introduction}

\subsection{International Programs in the Context of Globalization}

With the globalization of education, students have more options to obtain international experience. They can go abroad for further studies to obtain advanced degrees, but can also travel on short trips for "overseas learning experience" as part of their first degree program. Today, a great variety of international programs are also offered by universities within their home country. For example in Asia nowadays, students can earn a foreign degree without going abroad, because universities from the US, UK, Australia and Europe have opened their Asian campus. Local universities at home are also offering joint-degree or double degree programs with overseas institutions.

\subsection{Multinational Classrooms}

With the growth of international programs and the expanding network of exchange programs between local and foreign universities, even students who chose to enroll in a local degree program will likely find themselves studying with foreign classmates. However in practice, the clean and safe classroom atmosphere may not always be amenable to active interaction among foreign and local students. There appears to be a level of mistrust and apprehension between local and foreign students, especially among those with different physical appearances and distant cultural backgrounds. The most obvious is that the students tend to sit in groups with their own kind, forming local groups and foreign groups. In the classroom, while the local students are friendly and polite to their foreign classmates, but they still prefer to form study groups with local peers, and seem to minimize their interaction with foreign students once they are outside the classroom. 


\subsection{Objectives and Significance of the Study}

What are the major obstacles to intercultural socialization within a classroom? How can teaching methods be applied to foster positive intercultural socialization in the classroom, and enhance learning among youths in an intercultural environment? In seeking answers to these questions, this research applies collaborative teaching, and analyzes intercultural socialization behavior using the case of an undergraduate international program in Taiwan. Observing intercultural interactions may help to shed insights on the nature of prejudice and xenophobia among multinational youths. The perception and behavior of local Taiwanese students and their foreign classmates are examined through observation by the teacher, in combination with data collected from the multinational students through an open ended survey questionnaire.

\section{Literature Review}

In our highly globalized world, not only it is important to accept foreign cultures and people, but successful collaboration also depends on open communication which enables issues to be worked out constructively. Given the context of international programs and overseas educational experiences which universities have begun offering more recently, intercultural collaboration among students becomes critical for teaching and learning in a multinational classroom. Interaction in-class can also lead to a better understanding of other cultures, and enhance the student's potential for high-pay international jobs after graduation. The multinational classroom experience of today produces decision-makers, policy-makers and leaders with superior international potential for a better tomorrow.

Given that the multinational classroom in this study is located in Taiwan, it is also important to address the Chinese communication style. Literature on Chinese culture highlights harmony as the key concept in the Chinese society, governing all aspect of life, including relationships and interactions (Leys, 1983: 13). This trait can be exemplified by the fact that Chinese seldom contradict each other. A "no" may seem too brutal and direct and can hurt somebody: shang 傷 "hurt", ren 人 "human", shang ren: to offend people, which can also be said shang 傷“to hurt” he 和 “harmony”, qi 氣“air' (Chen, 2003, p. 63). Chinese prefer to mitigate the "no" by using attenuation formulas. They prefer to agree publicly to avoid one "loss of face" although they might be disagreeing privately. When people quarrel, neighbors will tell them to each give a bit because " $y i$ - qie ' $y i$ qie' $y i$ 以 he 和 wei 爲 gui 貴": "harmony is the most important thing".

This attachment to harmony which translates into a lack of direct criticism can also be related to the fact that Chinese culture is collectivist. In the large-scale survey conducted by Hofstede, Chinese subjects scored low in the Individual Index Value (IDV), thus confirming Chinese culture's collectivist dimension (Hofstede, 2005; Ho, 1986). Domino and Hannah (1987) reported that stories written by young Chinese students contained many more references to teamwork than was the case for their American counterparts.

The concept of "face" is also another key idea to understand why Chinese students hardly ever criticize their foreign peers, or dare not express their thoughts for fear of giving the wrong answer and "lose face". In his classic work, the Western sociologist Goffman (1955) defined the term "face" as "the positive social value a person effectively claims for himself by the line others assume he has taken during a particular contact. Face is an image of self delineated in terms of approved social attributes" (p. 213). Goffman further described social interactions as theatrical performances in which each individual has to choose a "line" or coherent pattern or verbal acts to express himself or herself, to maintain an image appropriate to the current social situation, and to secure a favorable evaluation from others (Bond \& Huang, 1986: 244).

Nevertheless, even with the Chinese concern with collective harmony, making efforts to save one's own "face" and other people's "face", socialization in a Chinese environment still does not always come naturally in any intercultural environment. Negative misinterpretations of Chinese polite reservations have happened at all levels, even among well trained national leaders with extensive international exposure. Even among themselves, the Chinese people also have conflicts with each other despite the harmony philosophy-it is not uncommon for "face saving" attempts to backfire even in mundane daily life situations. Clearly, intercultural socialization is an extremely complex process even when everyone has the very best of intentions to get along!

Socialization has been much studied over the years, including the negative social attitude of prejudice. For example, Allport's (1954) model of socialization posits that contact has a role in intergroup experiences, especially in schools among peers. Prejudice and even xenophobia (fear of foreigners) are common phenomena that may even be subconscious, and hence, past research has also looked at how prejudice is acquired (e.g. Dovidio, Glick, \& Rudman, 2005). However, there is a lack of empirical research on the topic of prejudice among youths, according to a review of intercultural relations literature by Rodriguez-Garcia and Wagner (2009). 
Social learning theory (Bandura, 1977) posits that behavior is learned by direct experience, suggesting that misconceptions about nationalities and ethnic groups, sex roles are formed through individuals' observations and experience in their social environment. Likewise, positive social conceptions and behavior-such as intercultural respect, understanding and trust-can also evolve in the positive classroom environment. This is because an international program brings students of different nationalities together in a classroom, and through socializing with each other during class activities, the students begin to form friendships and gradually co-develop a set of social behavioral norms over time. For example, Kitts (2006) studied the coevolution of social networks and behavioral norms among groups of people, and found that norms and behavior spread among friends in two ways, first though a contagion effect, and second through sanctions. Kitts (2006) also found that people would intentionally align their behavior with that of their "friends" or "us", just in order to differentiate themselves from "enemies" or "others".

However, past empirical studies of prejudice among youths provided inconsistent support for Allport's theory when it comes to social learning from parents, e.g. studies by Gniewosz \& Noack (2006a and b) found strongly positive correlations between high school students' racial prejudice and those of their parents, while studies by Aboud \& Shelagh (1984) and Aboud (1988) suggested that parents' attitudes get adopted only if it suited the children's way of thinking. Meanwhile, Dunn (1997) and Sinclair, Dunn \& Lowery (2005) found that prejudice transmission is bidirectional, in that it depends on how closely the child identifies with their prejudiced parents.

Given the modern dual-income family lifestyle, these findings have strong implications for today's classroom and the role of the teacher, particularly in the case of Taiwan. As early as 1992, according to Maccoby (1992), earlier conception of socialization as "the parent as a teacher" had moved towards placing greater emphasis on the "teacher-child exchanges". This situation is highly magnified in Taiwan today, as Taiwanese parents are assigning the responsibility of their child's proper upbringing to school teachers and even university teachers. High school teachers take on a heavier responsibility and often complain about parents' incessant and detailed inquiry about their child's behavior and how the teacher is managing it. Every university student in Taiwan has a mentor teacher, whereby each university teacher gets assigned approximately 30-60 mentees to provide counseling and guidance for, which includes personal life, career, education, etc. At times the mentor teacher may have to physically make a trip to visit the dormitory and home of the students to check on the well-being of their living environment. Official forms are required to be filed for every meeting or encounter with each mentee student, be it face-to-face, by Email, in the hallway, in the office, or anywhere both on and off the university grounds.

Besides acquiring prejudice from parents and teachers, social attitudes towards foreigners are also influenced by the extent of homogeneity between two groups of people, also known as homophily (Lazarsfeld \& Merton, 1954; McPherson, Smith-Lovin \& Cook, 2001). The reverse of this is xenophobia, where individuals feel repulsed by others who are very different from themselves. Thus, just as "birds of a feather flock together", individuals are likely to have a biased positive attitude towards those who are more alike to them in terms of physical appearance and communication style, and harbor a negative bias towards those who are more different from them in terms of physical appearance and communication style. Interestingly, teaching style has also been found to affect homophily/xenophobia in students. For example, Bovier and Boehnke's (1999) research on teachers and $9^{\text {th }}$ grade students from East and West Berlin found that liberal teachers with permissive "non-authoritarian" teaching styles who promote universalistic and humanistic political value produced more extremist "right-wing" youths who engaged in violent and xenophobic behavior. Although this study is an extreme case because it was conducted right at the end of the Cold War, it is possible that a normal, less drastic context might not produce such clear findings.

Therefore, the teaching methods that are selected by teachers for their courses can likely impact the evolution of social behavior, cultivating positive attitudes among the youths. It is also likely to dispel or reduce negative socialization, such as prejudice and xenophobia. Teachers have a key role in creating an environment that brings about positive intercultural socialization in an international classroom environment. In applying collaborative teaching techniques to a multinational classroom and examining how students feel towards foreign classmates, the findings from this research may provide insights for fine-tuning collaborative teaching and learning.

\section{Method}

\subsection{Subjects of the Study}

In order to obtain in-depth information on intercultural socialization among youths in an international undergraduate program, a class was identified for appropriateness of the course subject matter and an international mix of students. For this purpose, the course "Ethics and Social Responsibility" was chosen, 
because the course material lent itself to group discussions that were based on cultural differences, e.g. the concepts of right and wrong, human rights, racial and sexual discrimination, Western and Eastern ethical sense of responsibility. Such involved, subjective personal views are called upon in an ethics course, but not required for objective courses such as accounting or economics. In addition, the class was made up of students from more than 1 year-including Freshmen, Sophomores and Juniors, which provided a wider spread of youth respondents, covering representatives from almost the entire undergraduate program. In addition, they students in this course comprised a variety of nationalities-a mix of Haitian, Indian, Malaysian, Indonesian, Thai, American-Chinese, New Zealand-Chinese, Mongolian, with Taiwanese being the majority. The teacher observed these student participants throughout the entire course, and also collected data through an open-ended questionnaire which was given out to the students at the end of the course. In all, data were collected from 52 students. The questionnaire is provided in the appendix.

\subsection{Data Collection}

According to Shirky (2010), youths today want to be active players who have a part in the product (knowledge). They no longer value their role as simply consumers of knowledge, i.e. they want to collaborate in the knowledge creation process. A constructive way of looking at the collaborative process was also provided by Reither and Vipond (1989) who describe it as three-fold: coauthoring, workshopping and knowledge making. With this in mind, the course was intentionally designed to enhance participative collaboration in-class, whereby students had to form groups to complete an opinion-based assignment for every weekly class. Each class is 3 periods long, and each period comprises 50 minutes class and 10 minute break. During the first period, students listen to a teacher-led lecture (supplemented with PowerPoint, YouTube videos, case studies, and student project presentation where applicable) followed by Q\&A, after which, the teacher gives instructions for the group assignment. The second period is designated to group discussion among the students, with guidance from the teacher who is walking around from group to group to observe and give additional explanation and clarification. Sometimes the teacher also directs the students from one group to find out things from another group, so that the students have to mingle inter-group and the teacher does not have to keep repeating. It is also a way for the teacher to find out if her explanation was accurately understood by the first group that she had given explanations, and also to let the students practice communication skills - listening and transferring information and knowledge. In the third period, some groups may choose to present their term project (separate from the in-class group assignment), and the remainder of the period is used by the students to form a group consensus that culminates in a written group assignment submitted at the end of the class. The students usually take turns in writing up the assignment, sometimes it is usually done by 1 person (with better handwriting) for the entire group, sometimes they divide the assignment into parts and delegate the writing to a few members. Regardless of who ends up writing the assignment, the teacher makes sure that everyone engages in active discussion.

Thus, the students engage in active intercultural communication throughout the second and third periods, giving their opinions as inputs to intercultural knowledge creation through these socialization processes - doing group project, group discussion and written group assignment (writing as a collaboration, according to Reither and Vipond 1989). Moreover, engaging the student in collaborative learning-involving two-way communication, with mediation by the teacher-had been found transcend language barriers. Such collaborative method was found to be the most effective learning activity for imparting and retaining knowledge, in cases where the language of instruction is English as a Second Language, according to Sujarittanonta and Stuart's (2011) study on Thai undergraduates in an international program.

\subsection{Instrument}

With the research's focus on multicultural understanding and cooperation, the questionnaire was designed along the lines of related literature streams. First, on preference for similar people (homophily) and fear of foreigners (xenophobia). Second, on prejudice and intercultural socialization in the classroom. Third, students' personal experiences and their suggestions for improving intercultural collaboration through teaching and learning.

First of all, with regards to homophily and xenophobia, the questionnaire heading asked the students to "Choose 1 foreign nationality that you feel is the MOST DIFERENT from YOU", and the respondent had to specify the nationality. This is followed by a question on perception, which can be positive or negative (question 1). Further probing question asked for a description of why the respondent sees the "different" classmate in this way (question 2). Question 7 asked about the communication style of the foreign classmate both inside and outside the classroom. 
Second, intercultural socialization and prejudice was addressed by questions 3, 4 and asked respondents to list the difficulties they encountered with the foreign classmate, and their opinion on how well they work together, and questions 6 asked for what are the difficulties they think the foreign classmate face.

Third, questions 5, 8 and 10 gathered information on how intercultural collaboration could be enhanced in class, by asking the students on how they think their foreign classmates could integrate better, how the foreign classmate can increase their participation, and how the foreign classmate could improve their relations with the respondent.

In order to minimize cultural bias, two researchers jointly conducted content analysis of the completed questionnaires. This was also combined with ethnographic observations by the teacher throughout the entire course (a duration of 18 weeks), and the co-researchers' extensive experience living in different countries and teaching students of different nationalities.

\section{Results}

Of the 52 questionnaires obtained from this class, Haitian was perceived most of all as "most different" by 27 students (25 Taiwanese, 1 Taiwanese with US citizenship, and 1 Chinese-Indonesian). Indian was perceived second as "most different" by 7 students (all Taiwanese). Taiwanese was perceived as "most different" by 6 students (4 Haitians, 1 Indian, and 1 Taiwanese who grew up in New Zealand). Surprisingly, 9 Taiwanese students perceived classmates of Asian-Chinese ancestry as most different ( 3 for Malaysian, 2 Thai, 1 Mongolian, 1 Mongolian \& Malaysian, 2 Indonesian, 1 Hong Kong). Only 3 respondents (one Indian and 2 Taiwanese) chose not to specify any particular nationality as different from themselves. Content analysis enabled us to draw elements of intercultural dynamics among multinational youths, presented below.

\subsection{Homophily vs. Xenophobia}

When it comes to preference for similar people (homophily) and fear of foreigners (xenophobia), the Haitian (African) students were highly listed as being most different. However, contrary to expectations, physical appearance and language is not the most cited "difference", e.g. only 11 Taiwanese students see Haitian (African) and Indian classmates as different because of "their skin and language drew my attention", "their skin and eyes". "their skin color and hair", "usually have dark skin and they speak French", "their skin are black", "accent. face and hair", "because he has accent".

The overwhelmingly cited difference refers to the Haitian (African) students not because of their appearance or speaking accent, but in praise of Haitian's positive qualities such as their seriousness in studying, their communication skills, e.g. "they are really focus on class", "kindness and extrovertedness", "they do well on their school or class job", "usually friendly, easygoing, also talented about what they are learning, responsible for what they do", "enthusiastic", "studying hard and polite", "have high self expectation", "can express their opinions directly", "always concentrate (in class) and respect others". Whereas cultural differences are prone to generating interpersonal conflicts, the Taiwanese respondents in this study strongly exhibited a collective Eastern culture, demonstrating Eastern communicational style which avoids making direct criticism of their foreign classmates. Overall, what really stands out in the Taiwanese answers to the survey is how positive their comments of their foreign classmates are, how "politically correct". This feature can be related to the strong attachment to harmony within Chinese society (Bond, 1994; Bond \& Hwang, 1986).

Initially at the very beginning, skin color and language may have been the most obvious difference, but after seeing each other walking around in the university day in and day out, and having worked together in class for 18 weeks, it was the differences in personality as demonstrated through participation in-class that became more overpowering than physical appearance and accent. The Haitian students named Taiwanese as the most different from them, due to communication style and personality, e.g. "Their communication style is not satisfying", "They don't react when they feel bad about something", "they are not really friendly and sociable, they tend to be hypocrite", "they are lazy and have a satisficing attitude towards academic things". I.e., the Taiwanese do not communicate as much in class, to the point of being lazy, and because they are not expressive, they get perceived by the Haitians as being insincere.

In contrast, for the Taiwanese students, although language was cited by some as a barrier at the beginning, in-class interaction through group assignments and projects soon led Taiwanese students to appreciate the intelligence, new perspectives and insights offered by their foreign classmates. This was observable from the class seating dynamics-during the first 2-3 weeks of this collaborative teaching method, the students grouped themselves with their friends of similar nationalities and worked only within their own group, but very soon afterwards, the Taiwanese students began to discuss the assignments across the room to other Taiwanese groups. 
They not only spoke across the room, they moved their chairs into a more open arrangement. In addition, students also got out of their seats to walk over to another group at another end of the room just to look at what their classmates had written up. In the process of walking around, they also end up peeking in on the foreigner group and conversing with them.

Due to the Haitian and Indian student's verbal expressiveness and seriousness in class, the Taiwanese began to listen in on their foreign classmates' discussion. Later on, it became clear which students were better at the course. Soon, instead of tackling their assignments, weaker groups would simply wait to hear what the more verbal Haitian, Indian, and overseas Chinese were discussing. In effect, the outstandingly eloquent foreigners became automatically incorporated into the Taiwanese student groups, helping to produce written assignments that included ideas from the foreign students. Under such a situation, it is understandable why some foreign students viewed the Taiwanese as lazy.

Communication style is the major source of difference, even so for cases where physically similar nationalities were cited, e.g. the Malaysian classmate was perceived as most different to a Taiwanese, not because of appearance, but because of "communication"; a Mongolian was different because "I must communicate sincerely, and I can't laugh at their culture"; and a Chinese-New Zealand cited Taiwanese as being most different from him because they "are hard to communicate with, especially when it comes to the subject about personal opinions". In contrast, on a brighter note, Thai classmates were found to be rather excessively communicative, very friendly and chatty. Specifically, Thai-Chinese students were described by Taiwanese-Chinese as different because "they entertain a guest very kind" and "we gossip a lot of things", "they want to learn as much as possible" and "seems so interesting in our language", "always curious about what we say and want to know our topics that we're chatting".

\subsection{Prejudice and Intercultural Socialization in the Multinational Classroom}

Second, when it comes to prejudice and intercultural socialization in the classroom, local Taiwanese students feel that the Haitian students "ask questions, communicate with teacher all the time... so I think they are not necessary to improve their participation anymore", "positive of participation in the classroom". However, it was also observed that the Haitian students "tend to group together" and "they always bring up ideas in class, but outside of the classroom, they won't chat with us actively". On the other hand, the Haitians also feel that the Taiwanese "can improve their participation in the classroom by not being afraid to speak English out loud", "they have difficulties to develop relationship with foreign people". This suggests that the Taiwanese students, like most traditional Asians, tend to prefer listening and believing the teacher, rather than asking, disagreeing or voicing their opinions during class, even though once outside the classroom, they become quite talkative and opinionated. However, such respectful Taiwanese behavior in class is negatively perceived by the more participatory Haitians as "passive", "shy" and "lazy". Most importantly, the findings indicate that intercultural interaction takes place in the classroom because the students were given a group assignment to discuss and write up. But this interaction does not continue to outside of the classroom because there was no reason for them to get together to discuss things any more. Thus, to foster interaction after class hours, the teacher may have to design homework that required students to get together and hold discussions outside the class time.

\subsection{Students' Suggestions to Improve Intercultural Collaboration}

Third, from the students' personal experiences, suggestions to improve intercultural collaboration emphasized taking the initiative to start conversations such as "just go up and talk to them", "just talk to them frequently, try to figure out what they are thinking", "become more active and friend to them", "be the first one to wave hand and smile when I'm meeting them, not matter in or out of the classroom". Some respondents recognize a need to open up and understand another culture better, e.g. "talk more and try to understand their (Indian) culture", "share Taiwanese culture to them", "be more active and open mind". Suggestions also include searching for similarities, such as enjoying certain activities together, such as "hang out more with them", "talk to them, ask them to join our activity or bring them to some place that we will go", "lunch or dinner together". The students all realize the need to be self-motivated in starting conversations with their foreign classmates outside the classroom, but they seem to be waiting to be given a trigger to do so. Nevertheless, these are positive signs that the collaborative learning in-class could have stimulated students to think about taking initiatives to socialize more with their foreign classmates outside the classroom.

These last concluding findings suggests that collaborative teaching method can produce positive results in fostering intercultural communication in-class, and stimulate an interest in intercultural socializing outside the class. This presents an opportunity for the teacher to extend their intercultural collaboration efforts to outside of 
the classroom, e.g. to come up with learning tasks that required multicultural student groups to do field research together by organizing site visit assignments, study tours, meals and edutainment activities.

\section{Conclusion}

\subsection{Conclusion}

While physical appearance seemed to be the first obvious difference in a multinational classroom, this study found that over time, physical appearance is less of a difference than communication style. At the end of the 18 week course, only 11 out of 52 students cited skin color and hair as the characteristic that makes Haitians and Indians most different from them.

Rather, the most cited characteristic that makes students feel the difference is communication style at a deeper level, beyond accent and language. This could be attributed to cultural communication difference. For example, Haitian students as a whole are by nature more proactive and verbal in class, daring to ask the teacher questions, not shy to express their opinions during in group discussion with their classmates. Making an argument and taking a stand in such a manner was commended as being diligent and focused on the course subject matter. On the reverse, it was also negatively viewed by some Taiwanese as being overly aggressive and argumentative.

In reverse, the more expressive Haitians, Indians, and overseas Chinese found their Taiwanese classmates to be too shy. This was also negatively interpreted as a sign of laziness, indifference, or even hypocritical. This negative sentiment that was formed in-class may well likely lead to less willingness to communicate outside the classroom. Without an assignment for the teacher to grade outside the class, the students were not socially attracted to each other enough to continue communicating once the class period ended.

From the findings above, it suggests that communication style is the major obstacle for intercultural socialization in a multinational classroom. Differences in physical appearance are not an obstacle, because it becomes a non-issue with time. Students get used to skin, hair and accent after seeing each other day after day, sharing the same academic space. It was communication style that stood out as the major difference, even among students with more similar physical appearances (e.g. Asians, Chinese, Mongolians), although some communication differences were seen as positive, as in the case of chatty, hospitable Thai students.

Collaborative learning helped to dispel negative stereotypes that were portrayed by the mass media, cultivating a level of mutual respect and admiration among the students in a multinational classroom, resulting in successful knowledge sharing and joint-knowledge creation among multinational peers. However, this study found that while collaborative teaching methods (involving a lot of in-class group discussions and group projects) successfully fostered intercultural communication and intercultural peer-to-peer learning, the communication occurred only inside the classroom, and not beyond.

\subsection{Limitation of the Study}

A limitation of this study is that this was conducted only on one multinational class in one university in Taiwan, with only 52 respondents, for only 1 semester lasting 18 weeks. Because the university is located in Taiwan, this class also had Taiwanese and Asian-Chinese as the majority. A longitudinal study involving more samples of youths at both high school and university levels from multiple countries are needed in order for the findings to be more generalizable across the globe. In addition, this study applied collaborative teaching and learning only inside the classroom, a follow up study needs to be conducted to better understand intercultural communication and socialization outside the classroom.

\subsection{Implications}

Nevertheless, the findings suggest that there is a crucial role for the teacher in fostering intercultural collaborative learning. Several misunderstandings and cultural conflicts might have been resolved in the classroom, had the teacher briefed the students about differences in communication style at the very start, especially the communication style of the predominant culture. For example, in the case of this Taiwan international program, Taiwanese students were the majority. Findings also suggest that teachers, educational administrators and policy makers have a crucial role in developing students' intercultural competence by implementing collaborative learning methods in the multinational classroom.

Findings from this study also have implications for intercultural corporate training programs designed for foreign expatriate managers and host country employees. Usually cross-cultural training programs for businessmen tend to emphasize communication theories and stereotypes, missing out on theory and empirical studies from the education field. Increasingly, corporate training is also conducted online using culture-shock cases, and substitute face-to-face interaction with video conferencing. Thus, this deprives the trainee of hands-on learning 
by doing, and the classroom inter-group dynamics also cannot happen. Collaborative learning methods are likely to provide a better intercultural orientation for multinational business industries.

\section{References}

Aboud, F. (1988). Children and prejudice. Oxford: Blackwell.

Aboud, F., \& Shelagh, S. (1984). The development of ethnic attitudes. A critical review. Journal of Cross-Cultural Psychology, 15, 3-34. http://dx.doi.org/10.1177/0022002184015001001

Allport, G. (1954). The nature of prejudice. Cambridge: Addison-Wesley.

Bond, M. H. \& Huang, K. K. (1986). The Social Psychology of Chinese People. In M. H. Bond (Ed.), The Psychology of the Chinese People (pp. 213-266). Oxford: Oxford University Press.

Bond, M. H. (1994). Beyond the Chinese Face, Insights from Psychology (7th ed.). Hong Kong: Oxford University Press.

Bovier, E., \& Boehnke, K. (1999). Do liberal teachers produce violent and xenophobic students? An empirical study of German ninth graders and their teachers. Teaching and Teacher Education, 15, 815-827. http://dx.doi.org/10.1016/S0742-051X(99)00017-7

Chen, Y. C. (2003). L'enseignement du français langue étrangère à Taiwan. Analyse linguistique et praxéologique. Unpublished doctoral dissertation. Université catholique, Louvain, Belgique.

Domino, G., \& Hannah, M. T. (1987). A comparative analysis of social values of Chinese and American Children. Journal of Cross-Cultural Psychology, 18(1), 58-77. http://dx.doi.org/10.1177/0022002187018001007

Dovidio, J., Glick, P., \& Rudman, L. (2005). On the nature of prejudice. Fifty years after Allport. Oxford: Blackwell Publishing. http://dx.doi.org/10.1002/9780470773963

Dunn, J. (1997). Effects from the study of bidirectional effects. Journal of Social and Personal Relationships, 4, 565-573. http://dx.doi.org/10.1177/0265407597144010

Gniewosz, B., \& Noack, P. (2006a). Intergenerationale Transmissions - und Projektionsprozesse intoleranter Einstellungen $\mathrm{zu}$ Auslandern in der Familie. Intergenerational transmission and projection processes of intolerant familial attitudes towards foreigners. Zeitschrift fur Entwicklungspsychologie und Padagogische Psychologie, 38, 33-42. http://dx.doi.org/10.1026/0049-8637.38.1.33

Gniewosz, B., \& Noack, P. (2006b). Adolescence intolerance, perceived parental intolerance, actual parental intolerance, and projection. Unpublished document. Universitat Jena, Germany.

Goffman, E. (1955). On Face-work: An Analysis of Ritual Elements of Social Interaction. Psychiatry: Interpersonal and Biological Processes, 18 (3), 213-231.

Ho, D. Y. F. (1986). Chinese patterns of socialization: a critical review. In M. H. Bond (Ed.), The Psychology of the Chinese People (pp. 1-35). Oxford: Oxford University Press.

Hofstede, G., \& Hofstede, G. (2005). Cultures and Organizations, Software of the mind (2nd ed.). New York: McGraw-Hill.

Kitts, J. A. (2006). Social influence and the emergence of norms amid ties of amity and enmity. Simulation Modelling Practice and Theory, 14, 407-422. http://dx.doi.org/10.1016/j.simpat.2005.09.006

Lazarsfeld, P. F., \& Merton, R. K. (1954). Friendship as a social process: A substantive and methodological analysis. In M. Berger, T. Abel, \& C. H. Page (Eds.), Freedom and Control in Modern Society (pp. 8-66).

Leys, S. (1983). La forêt en feu. Paris, Hermann, p. 13.

Maccoby, E. (1992). The role of parents in the socialization of children: An historical overview. Developmental Psychology, 6, 1006-1017. http://dx.doi.org/10.1037/0012-1649.28.6.1006

McPherson, J. M., Smith-Lovin, L., \& Cook, J. M. (2001). Birds of a feather: Homophily in social networks. Annual Review of Sociology, 27, 415-444. http://dx.doi.org/10.1146/annurev.soc.27.1.415

Reither, J. A., \& Vipond, D. (1989). Writing as collaboration. College English, 51(8), 85-867. http://dx.doi.org/10.2307/378091

Rodriguez-Garcia, J., \& Wagner, U. (2009). Learning to be prejudiced: A test of unidirectional and bidirectional models of parent-offspring socialization. International Journal of Intercultural Relations, 33, 516-523. http://dx.doi.org/10.2307/378091 
Shirky, C. (2010). Cognitive Surplus. New York: Penguin Group.

Sinclair, S., Dunn, E., \& Lowery, B. (2005). The relationship between parental racial attitudes and children's implicit prejudice. Journal of Experimental Social Psychology, 41, 283-289. http://dx.doi.org/10.1016/ j.jesp.2004.06.003

Sujarittanonta, L., \& Stuart, B. E. (2011). Imparting Knowledge Using English as a Second Language: Knowledge Acquisition and Knowledge-Based Behavioral Changes. Prince of Sonkla University Journal of International Studies, 2(1), 27-40.

\section{Appendix A:}

\section{The Questionnaire}

\section{Choose 1 foreign nationality that you feel is the MOST DIFFERENT from YOU.}

1) How do you perceive your foreign classmates (specify: ___ _ E.g. Haitian, Indian, Malaysian, Chinese, etc.

2) Why do you see them in this way? Please describe.

3) Did you have difficulties with your foreign classmates? Why?

4) Do you think your foreign classmates work well in the classroom with you? Why?

5) Do you think your foreign classmates could integrate better? How?

6) Do you notice some difficulties of your foreign classmates? How and why?

7) How do you perceive their communication style inside and outside of the classroom? Do you have any difficulties with it? How and why?

8) Do you think your foreign classmates could improve their participation in the classroom? If yes, how?

9) What do you think you could do to improve the relations with your foreign classmates?

10) What do you think your foreign classmates could do to improve their relations with you?

\section{Copyrights}

Copyright for this article is retained by the author(s), with first publication rights granted to the journal.

This is an open-access article distributed under the terms and conditions of the Creative Commons Attribution license (http://creativecommons.org/licenses/by/3.0/). 